\title{
Both, and: Transmedicalism and resistance in non-binary narratives of gender-affirming care
}

\author{
Lex Konnelly \\ University of Toronto
}

While gender dysphoria is a real and acute distress for many transgender people, it is not universal, and it is experienced and oriented to in a myriad of ways. However, its status as a prerequisite for gender-affirming care can lead trans people to feel compelled to amplify its salience in their pursuits for medical support. Through a critical discourse analysis of non-binary healthcare narratives, I trace the relationship between linguistic practices in these care interactions and the gender and sexual logics of the transmedicalist model of transgender care. With a focus on excerpts that center on individuals' descriptions of dysphoria in the consultation room, I contend that these experiences are not straightforward accounts of assimilation to transmedicalist expectations. Rather, when read from a trans linguistic perspective, these strategies are examples of non-binary patients enacting their own interventions on a process over which (it may seem) they have minimal control and present a critical thirding (Tuck 2009) of a dichotomous view of either transnormativity or resistance.

\section{Introduction}

Though the standards of care for transgender people have improved significantly in the last few decades, many policies continue to gatekeep access to gender-affirming medical support. ${ }^{1}$ A key barrier to accessing this type of care is a diagnosis of gender dysphoria, as defined in the fifth edition of the Diagnostic and Statistical Manual of Mental Disorders (DSM-5; American Psychiatric Association 2013). Research on transgender speakers' linguistic practices in healthcare interactions (Speer 2011; Speer and McPhillips 2013; Zieger 2016, Borba 2017, 2019; inter alia) has shown that practitioners' prerequisites for granting access are largely based on the DSM-5's diagnostic criteria for dysphoria, defined as "a marked incongruence between one's experienced/expressed gender and assigned gender," enduring at least six months, and manifesting in at least two of a number of DSM-5-sanctioned desires for physical characteristics or social recognition (American Psychiatric Association 2013: 302.6). The medical institution's subscription to these narrow criteria for transgender identity has resulted in an impression within trans communities that there is one ratified narrative of transgender experience: one that few individuals truly experience, but that all are expected to emulate. This has led to a further impression that accessing gender-affirming care is a test, where patients must 'do' gender (West and Zimmerman 1987) or present their identity in a particular way.

Medically-based, normative understandings of sex and gender place undue restrictions on the autonomy of many (if not all) trans people, both binary and non-binary, and the effects of these medicalized narratives are diffused throughout institutions (for discussion, see Johnson 2015; Vipond 2015). In the context of medical interactions, non-binary individuals in particular report an expectation of staying within

\footnotetext{
${ }^{1}$ Gender-affirming in this context does not just refer to the quality of the care received, but rather to the specific kind of care that is sought: that is, medical support (such as hormone therapy or access to surgical procedures, etc.) that may provide individuals with greater ease in their embodiment.
} 
sex and gender binaries in doctor-patient conversations, in large part due to the belief that an intelligible binary identity is a requirement for being accepted into care even if "deception, fraud, or misrepresentation [is] absolutely necessary" (Zieger 2016: 40). Non-binary patients are also constrained by the fear of not being recognized as "trans enough" - a pressure to mirror dominant binary narratives (Garrison 2018). The hierarchy of "trans enough" refers to the conception, both inside and outside of transgender communities, that some transgender identities are more authentic than others. This may refer to the types of experiences that individuals are expected to have in order to be 'really' transgender (such as feeling they were "born in the wrong body," having "always known" that they were transgender, etc.), or it may refer to the differential validation of some transgender identities over others. Core to concerns about being "trans enough" is the notion of the most 'authentic' trans identity as moving from one defined binary position to the next, and where an individual's experience of gender can be distilled into a historically-consistent narrative that adheres to cisheteronormative expectations. This framework - to which transgender people's presentations and experiences of gender are held accountable - is described by Johnson (2016: 465) as transnormativity, which "structures transgender experience, identification, and narratives into a hierarchy of legitimacy that is dependent upon medical standards."

To identify with a gender positionality outside of the binary (and, especially, outside of the transnormative) has historically meant losing access to care, and as a result, non-binary patients may find themselves using different language to describe their experience than they would in other contexts, simply to gain access to the care that they need. To illustrate, I present excerpts from one-on-one ethnographic interviews with non-binary people currently in the process of accessing gender-affirming care in Ontario, Canada. ${ }^{2}$ These interviews are from ongoing doctoral research, and examples were drawn from conversations with a sample of eight individuals at the time of writing. Collaborators are of various ages, socioeconomic statuses, racial identities, and non-binary gender identities. The examples below focus on one salient concern: how individuals orient to the medicalized notion of "dysphoria." These conversations highlight the ways in which linguistic performances are crucial, materially-impactful parts of establishing recognition as authentically "trans enough" in medical encounters and, in some cases, of invoking aspects of the "true transsexual" (Benjamin 1966) narrative as per the expectations of the medical system. However, reading these excerpts from a trans linguistic perspective (Zimman 2020), a theoretical orientation to the study of language and gender that centers trans practices and subjectivities, exposes how the moments described are not straightforward cases of assimilation, conformity, or 'passing' (Bailey 2000; Borba 2019). Focusing on two discursive strategies - (1) intensification and (2) historicization of "suffering" - as well as metalinguistic reflections on how they are carefully and precariously constructed in interaction, I argue that my research collaborators endeavor to convey an approximate truth that includes sufficient information for the situation, providing nuance to previous analyses that characterize trans patients as misleading their doctors (Speer 2010) or submitting to transnormative discourses in a way that forecloses the possibility for agency (Borba 2017). Rather, these strategies are examples of non-binary patients enacting their own interventions on a process over which it may seem that they have minimal control. Further, these practices represent a critical thirding (Tuck 2009) that troubles a dichotomous view of either transnormative capitulation or resistance to transmedicalist expectations.

The goal of this work is not only to contribute to growing scholarship on the complexity and creativity of linguistic practice within trans communities and how it is impactful in trans people's lives, but also to

\footnotetext{
${ }^{2}$ As the healthcare system is a complex institution, I left identification with this criteria open to the interpretation of participants. In practice, this refers to individuals who are at any stage of pursuing access to components of medical transition that has involved interaction with healthcare practitioners. In Ontario, access to gender-affirming care is primarily mediated through general practitioners, whereby an individual meets with their doctor and discloses their desire for this medical support. In instances where a patient's primary care provider is unsupportive or otherwise unwilling to grant access, they may either be referred to another doctor (perhaps at a "gender identity clinic" like CAMH in Toronto or CHEO in Ottawa) or they may seek another doctor on their own. While interactions with many medical professionals came up as a topic of conversation in the interviews, the excerpts I present here focus solely on interactions with general practitioners in the context of the consultation room.
} 
contribute to identifying and dismantling the barriers that exist for trans people in accessing competent, truly-affirming healthcare. In the following section, I provide some additional background on the significance of the medicalization of transgender experience for trans people, as well as an example of the cultural discourses (Kiesling 2007) from within transgender communities that employ the medical model in processes of distinction (Bucholtz and Hall 2005) between 'authentic' and 'inauthentic' transgender identities, highlighting how these discourses are impactful in medical contexts themselves. Sections three and four describe the methodological approach and present the analysis of select interview excerpts, respectively. In the final section, I scaffold my earlier discussion, concluding with an elaboration on a more nuanced view of reproduction of transnormativity or resistance (Tuck 2009).

\section{Community discourses and medicalization}

Transgender communities have had at best an ambivalent relationship to the medical model of transgender identity from the time it was formally introduced in the DSM-III (American Psychiatric Association 1980; Johnson 2015). Activists, advocates, and scholars alike consider the model at once empowering and also pathologizing (Burke 2011): while it provides a means through which some transgender individuals can obtain the medical supports that they need, it also operates as "a normative standard to which transgender people's interactional experiences of gender are held accountable in medical, legal, and social interactions" (Johnson 2015: 803).

Dysphoria has been used in the transgender community for decades in reference to the discomfort community members feel in relation to their sex assigned at birth (see also Devor 1996; Cromwell 1999); in the DSM, however, this discomfort is framed as mental illness and as a symptomatically-diagnosable pathology. Perhaps because of its significance in the current medical model of transgender identity, the role gender dysphoria plays in determining transgender experience is the topic of much debate within trans communities. Belief in dysphoria as a defining feature of what it means to be transgender is the linchpin of transmedicalism, an ideology stipulating that both gender dysphoria and (a strong desire for) medical transition are required in order to be considered 'genuinely' transgender. Often referred to in short, by themselves and others, as simply transmedicalists (and sometimes as truscum or transfundamentalists), those who subscribe to this view ratify medical authority in regulating transgender experience, insisting that deviating from the established medical model undermines public acceptance of trans communities and trivializes 'authentic' trans experiences. They criticize those deemed "transtrenders," individuals who 'inauthentically' claim to be transgender in the absence of medicalized criteria, particularly gender dysphoria. Example (1), a post taken from the active online subreddit $r$ /truscum, provides one illustrative view. ${ }^{3}$

(1) "this is what all neopronoun users sound like lmfao" ( $r$ /truscum, December 2020)

1 i know $i$ just went by peta and mark last month but can you guys call

2 me tommy now 0.00 I'll change it again in a month to Kai but please

3 call me tommy now it makes my euphoria go brrrrr 00000 if you won't

4 call my pronouns cat/catself and refer to me as cat gender then you

5 are transphobic, even if you are a dysphoric trans person yourself

6 who transitioned into a male, female, or they/them!! 20 you also

7 have internalized transphobia even if you are trans but won't call

8 me Kittyself I get my information off of tumblr and tiktok

9 AND IT IS A VALID SOURCE!!!

10 links or evidence and its all 11-15 year olds who think these things

11 but it makes my brain and non dysphoric body go brrrr uwu im

\footnotetext{
${ }^{3}$ While truscum is considered by some to be a derogatory term, it is generally widely - and at times proudly - claimed within this particular transmedicalist community, as evidenced by the forum name.
} 
12 such a smol kitty!!!!

13 hard time getting their pronouns normalized and their preferred name

14 too!! but $i$ don't care!! my issues are more important

In the above text, the user performs a characterological figure (Agha 2007) representing "all neopronoun users;" that is, individuals who use innovative third person pronouns (for example, ze/zim/hir, or nounself pronouns such as catself as in the case above) as their personal pronouns of reference. In this display, they articulate a number of metalinguistic and metasemiotic practices that they associate with this persona and in doing so, mark them as the target of mockery. From this performance, we can deduce that the average "neopronoun user" allegedly changes their name frequently; uses a lot of 'soft' affective emojis like flowers, hearts, and pleading faces; orients to gender euphoria rather than dysphoria; and uses expressions like smol, $u w u$, and go brrrr, online indices of quirkiness and cuteness. It can also be inferred that neopronoun users are young and retrieve their information on gender identity and experience from 'unreputable' online platforms like Tumblr and TikTok, where "there isn't any factual links or evidence" (lines 9-10). The author responsibilizes these individuals for the difficulty that other trans people have in having their names and pronouns recognized, characterizing neopronoun users as selfishly prioritizing their own experience (which is supposedly frivolous and uninformed by medical science) at the expense of others' (who are supposedly more deserving and educated by medical criteria). In Bucholtz and Hall's (2005) terms, this text is a performance of distinction, whereby the author differentiates between the non-dysphoric (line 11) neopronoun user, a target of ridicule who is implicitly not authentically transgender and also likely nonbinary, and the dysphoric trans person, who suffers as a result of their conflation with the previous category. Interestingly, non-binary people (or at least the nominalized "they/them," contrasted with "male" and "female") can be considered by the poster to be authentically trans - as long as they are dysphoric and have medically transitioned (lines 5-6).

As the saying goes, there is a lot to unpack here. Note that this is only one instantiation of transmedicalist rhetoric, and transmedicalists' subscription to these and similar expressions of derision are likely variable; unfortunately, a deeper dive into the discursive construction of online transmedicalist personas are beyond the scope of this paper. However, it is necessary to contextualize how dysphoria - its presence, its absence, and how this intersects with certain transgender identities, particularly non-binary ones - are often framed in online representations by other trans people. Given the significance of online trans communities for resource-sharing and networking (Dame 2013) and as places where many trans people turn to express and cultivate their identities in greater relative safety, these representations are critical sitings of ideologies that shape (especially young) trans people's self-perceptions and behaviour (Jones 2019). Along with hegemonic depictions of trans people in the mainstream media, online communities - and the content that circulates there - are often backdrops against which trans people negotiate their sense of self. In the interview excerpt in (2), Grey describes the complex ideological relationship between dysphoria and authenticity in online spaces:

(2) Grey (29/White/Genderless, trans, non-binary $)^{4}$

1 I have definitely had a different experience than I think a lot of binary trans people

2 Um as far as not really experiencing body dysphoria like that was my biggest fear going in like I was like <I don't think I don't know how to respond to that question if [the doctor] asks me that> because I'm afraid that I'll be turned away or that he will deem me like whatever

3 Not trans enough like

4 <you shouldn't be going on hormones if you- you know aren't in terrible suffering with your physical body>

\footnotetext{
${ }^{4}$ Demographic information is in the following format: age/race or ethnicity/gender identity. This information was collected via free-form answers from collaborators themselves and replicated faithfully here.
} 
5 Which is also such a dominant narrative online

6 That like of course that starts to seep into your own experience of your own identity

7 I think it's a combo between like there is a lot-- there is a dominant representation of that being trans means that you are suffering in your body um

8 Before and that hormones and surgery are a way to escape that

9 But there's also such a dominant narrative of people explicitly saying that <if you don't experience that you're not trans>

10 There's so so many people who as you know I think a lot of them are are super young um

11 And are-- have experienced an incredible amount of trauma through the healthcare system through their experience of transness and it has been really traumatic for them and

12 And that I might experience transness not as an intense suffering and that my gender identity is like totally different and expansive and like doesn't really fall within that

Though they do not (at least in this excerpt) use any of the labels transmedicalist, truscum, or transfundamentalist, Grey does seem to speak to these positionalities in identifying the source of their own fears of being asked about dysphoria by their doctor. In their observations of the pressure to present as dysphoric and suffering that is spread throughout trans communities, particularly online (line 5), Grey acknowledges that this "starts to seep into your own experience of your own identity" (line 6). They describe how in transmedicalist virtual spaces, dysphoria is constructed as a baseline measurement both for medical access and 'authentic' trans identity more generally, with some explicitly maintaining that absence of suffering in one's physical body (line 4) entails that one is not transgender (line 9). However, Grey ultimately holds the medical institution responsible for this ideology, proposing that it originates with (predominantly young, online) community members who have experienced significant trauma in the medical system. As is apparent in the excerpts presented below, in the "on the ground" moments of healthcare interactions, the internalizing forces of these intracommunity representations are often given equal (or near-equal) weight as the normative pressures of the medical institution. What's more, they consciously inform individuals' linguistic strategies in the process of seeking care.

\section{Data and method}

The data collected are in the form of semi-structured one-on-one interviews with non-binary people currently in the process of seeking gender-affirming care. Because there is currently no national standard of care or procedure for transgender people in Canada, and due to the structural variation of healthcare systems by province, this study focuses on individuals within Ontario only. Participants were recruited via the 'friend of a friend' snowball method (Milroy 1987). All names are pseudonyms, most of which were chosen by participant-collaborators themselves. Interviews were transcribed and coded in NVivo (QSR International 2020), then analyzed for trends and common features pertaining to language use and language strategies in patients' care visits. As noted previously, this analysis is restricted to discussion of dysphoria and its ideological relationship to 'authentic' trans identity.

The analysis is qualitative and takes Critical Discourse Analysis (CDA) as its primary perspective (Fairclough 2013; inter alia). Concerned with identifying relationships between language and systems of power, CDA's utility lies in exploring the imbrications between language and social-institutional practices, and of 'wider' political and social structures, making it ideally suited as an approach to analyzing the effects of institutions on linguistic practice. I take a sociocultural approach to CDA that follows foundational studies of language and power (Fairclough 1989, 1995), emphasizing the need to relate discourse structures and discursive practices to social and political structures at the macro-level.

Critical discourse studies have been a productive site of research in language and healthcare interactions (Wodak 1996; Candlin and Candlin 2003; Brown et al. 2006; Jones 2013; inter alia). Yet as 
noted by Jones (2015: 847), while the vast majority of discourse analytical research in health communication has taken place in clinical settings, "there is a growing recognition that many of the most important conversations that people have about health do not occur in clinics and hospitals, but rather in places like bedrooms and around dinner tables [...] what Brown and his colleagues (2006: 95) call 'wildtrack communication'." Additionally, although critical discourse studies have a long tradition of zeroing in on the ways in which the power of dominant groups emerges in their own discourse, those who are the targets of such power - and their discourses of resistance - have been much less studied (van Dijk 2015: 479). In pursuing a discourse-analytic approach to the linguistic mediation of institutional transmedicalism in non-binary peoples' own narratives, this study is situated in both of these gaps. The intent of this analysis is not to cast yet another surveilling eye on the innovative, creative survival practices of trans people, but rather to celebrate them - and in doing so, to show how the medicalized notion of dysphoria fails to capture the nuance of the expansiveness of trans experience, and how a reimagining of it is crucial to moving towards truly-affirming care.

\section{$4 \quad$ Linguistic strategies in talk about gender dysphoria}

The necessity of dysphoria as a core criterion for access to care often leads trans patients to feel compelled to amplify its salience in their desire for medical support. The remaining examples present some specific overlapping linguistic strategies for doing so - notably, (1) the intensification of feelings of dysphoria and (2) the historicization of dysphoric "suffering" - as a means to communicate the requisite need and certainty for medical support. The veracity of dysphoria is often inferred from its longevity, and it is common for trans patients to be asked by their doctors how long they have been experiencing discomfort in their assigned gender. In example (3), Theo recounts an interaction with their doctor where they were asked to describe their gender in their youth as part of a consultation for a gender-affirming procedure:

(3) Theo (19/Mixed/Transmasculine non-binary)

1 Um when I was like first having the conversation with her about like top surgery like I-- I do remember like I was like going through like my experience in grade ten and um

2 Like saying that like at that point I presented very like femme but like feeling like I was like but this is because of this and this and this and this and like justify? That kind of thing um

3 So she didn't like think that was who I was like

4 In like this is what was going on in my life I was doing this like because like I went to this very conservative high school and like I wanted to like fit in with it and like I wanted to like make connections with people and the only way I saw I could do that was like

5 By presenting as very female um

6 But like feeling like I had to like harp on the like

7 That was a-- that was a lie and I was so sad because I was doing that at the time

8 Versus like that was just something that happened and now that's not what happens anymore these things change like that's fine

Theo describes recasting their previous gender expression as having been rooted in dysphoria, discomfort, and dishonesty, even though that was not the case at the time. Since they presented very "femme" (line 2) at this point in high school, Theo felt it was necessary to justify this difference from their current gender expression "so she didn't like think that was who I was" (line 3). Theo not only historicizes their dysphoria by "harp[ing] on" (line 6) how their previous feminine expression was "a lie" (line 7), but they intensify its effects, describing themself as "so sad" (line 7), restricted by the peer relationships at their "very conservative high school" (line 4). Considering the dearth of medical knowledge doctors typically have regarding LGBTQI2S+ care (Obedin-Maliver et al. 2011; Sharman 2016), trans people must choose 
between aligning to what they think their doctor is most likely to recognize about trans experience or educating their doctor on the nuance of their experience, which may or may not be successful and could result in a denial of access to care. For Theo, the fact that they expressed their gender differently throughout their life is a non-issue; they are matter of fact in their assertion that "that was just something that happened and now that's not what happens anymore these things change" (line 10). However, in anticipation of their doctor's desire for a neat and coherent narrative, they obliged with a diachronic, static, and acute experience of dysphoria that is anchored in their adolescence, affirming their current experience of trans identity as institutionally 'authentic' through a historic narrative of suffering.

Theo exemplifies how trans people are familiar with invoking the language of the institution in order to get the access that they need, and strategic essentialism (Spivak 1988) for the purposes of the doctorpatient consultation can be an effective means to an end. In essentializing an experience of transgender identity that they believe will be intelligible to their doctors, Theo - and other participant-collaborators engage in a process of adequation (i.e., constructing sufficient similarity with; Bucholtz and Hall 2005) with other trans people seeking gender-affirming care: even if they do not straightforwardly align with the narratives they construct for their healthcare providers, they are nonetheless equally deserving of the same care. But it is not quite so easy. In (4) below, Jameson articulates the tightrope that trans patients must walk in their medical encounters - notably, that one mustn't over-perform.

(4) Jameson (18/Puerto Rican/Transmasculine, non-binary, genderqueer)

1 When I was first in september recently to see uh

2 The doctor at [medical center] to ask for um [hormone blockers] and talk about getting testosterone um

3 At that point I definitely had that weird dysphoric fear-of-thegovernment desperation to start

4 It was less that I felt the need to present more masculinely or something it was more of like I felt like I needed like

5 To somehow prove that I was trans enough if that makes sense

6 I don't think I over-exaggerated what I was dealing with at the time but I definitely put in a bunch of-- I definitely made sure to include only negative information about what I was feeling because I was afraid

7 I don't see why my fears would have happened but I was afraid of you know <oh your dysphoria's not that bad you can wait a little longer to have this appointment> or <I'll schedule you a little later to have this appointment like it's not that bad> um

8 Like I felt the weird need to prove to my doctor that I was really sure about this and that like I-- instead of saying like <yeah I'm sure I'm in the positive mental space to consent to this $>$ like $<I^{\prime} m$ in desperate need and I need this>

9 I was also afraid that like it was a weird mixture of trying to express to my doctor that I was in need and upset and in emotional turmoil that I needed quick healthcare cause I also knew it was gonna take forever

10 But I also was afraid that if I let something slip about my mental illnesses and my bad habits that she wouldn't give me a prescription or she wouldn't refer me to the doctor

Jameson is keenly aware of the significance of dysphoria in the interaction and in fact places it above sartorial gender expression in the hierarchy of important evaluative components, noting that they felt less compelled to present "more masculinely" (line 4) than they did to "prove" that they were trans enough to receive care (line 5). Parsons' (1951) classic discussion of the doctor-patient relationship proposes that becoming sick involves entering into a special social role: the "sick role". This role has particular rights and obligations and is special in entitling individuals to social support from others, protecting them from the consequences of sickness and providing a basis on which to withdraw from their usual social obligations. 
The gender-affirming care interaction is a unique one in that transgender people are made patients simply by virtue of their transness and must deftly straddle the boundary between presentation of the self as both sick and not-sick. While the diagnosis of gender dysphoria is typically a requirement for gender-affirming medical support in Canada and is thus an 'illness' as far as the healthcare system is concerned, individuals' experience of dysphoria must not be so acutely distressing as to raise concerns about their 'stability,' which could risk bringing the accuracy of their experience and, by extension, the likelihood of their care, into question. As such, it is not only transmedicalism that must be navigated but also ableism.

Jameson also highlights a common prevalent concern regarding refusal: the timeliness of care. As a result of the medicalization of trans bodies, which views trans embodiment as abnormal and pathological, the set of medical standards in primary trans healthcare recommend a slow and controlled set of steps to access care. Clear in Jameson's narrative is the fact that denial itself is not something that necessarily occurs in one explicit and finite speech act. While some trans people certainly do experience outright denial, denial occurs on a continuum, fluctuating between categorical rejection and a reluctance that is deleterious in impact if not in intent. For Jameson, the intensification of their dysphoria - their inclusion of "only negative information" about their experience (line 6), and expression to their doctor that they were in desperate need (line 8) - was a necessary intervention on the prolonging of this process. Other participant-collaborators reported the necessary paperwork getting lost or languishing in filing cabinets; ignored requests for followups; unreturned phone calls and emails; circular referrals; and other forms of stagnation in administrative advancement. It is certainly possible that some physicians stall access out of a concern that they lack the requisite knowledge to provide proper care; however, as Abelson (2019) notes, this hesitation is itself a testament to how providers are embedded in the gender and sexual logics of the transmedicalist space, and the frustration that this reluctance causes has been widely noted in both scholarly and activist discourses on transgender medicine. Given the extremely elevated rates of depression, anxiety, and suicidal ideation among trans people (Bauer et al. 2013; Bauer and Scheim 2015), access to this care is often essential to individuals' well-being.

\section{Discussion and conclusions}

Based on the metalinguistic observations in the excerpts above, it is apparent that dysphoria must be centered in the doctor-patient interaction, but delicately so. These narratives show how presenting an experience of dysphoria is more than simply disclosing discomfort and distress: a number of interactional and discursive processes coalesce into an overarching performance of dysphoria that is specific to the context of the interaction. It is through careful intensification and historicization of dysphoria that its relevance is constructed. And yet, this construction is precarious in that it can easily be undone or rendered unbelievable. Yet a devastating truth is that in meeting this transmedicalist expectation (i.e., in presenting themselves as 'authentically' dysphoric and thus deserving of care), participant-collaborators' healthcare is deeply compromised. In getting one need met, they must sometimes forgo others - such as the ability to ask exploratory questions and express concerns about their medical care. A striking example of this comes from Keaton in (5), who in the below excerpt has just finished describing a visit which they generally evaluated positively. However, upon follow-up, they muse on the role their own linguistic practices played in how their appointment ultimately concluded:

(5) Keaton (29/White/Opts out of identifying gender)

1 L: So it sounds like maybe you'd characterize it as a good visit?

2 K: Yeah I think so she was great

3 And at first I'm thinking <maybe she's just lovely and maybe she would have been really wonderful regardless and there was nothing to worry about>

4 But then afterwards I wondered maybe it wouldn't have gone so well if I didn't use specific language or whatever?

5 L: I mean you can't tell right it's so hard to know

$6 \mathrm{~K}:$ Yeah 
7 L: What do you mean by that? Do you think you were really careful about what you said to her or how you said it? Or

$8 \mathrm{~K}$ : [pause $0.5 \mathrm{sec}$ ] So at first she was asking me questions and then she was like <do you have any questions> and I [loudly] did

9 But I was just so thankful so I was like <I don't wanna say anything in case like anything I ask suddenly like erases this whole thing from happening>

10 And I had two concerns that I'd read about on this-- internet that have since turned out to be total lies but I didn't want to ask them because like

11 Anyone with like [loudly] enough dysphoria wouldn't care if their bladder prolapses

$12 \mathrm{~L}: \mathrm{Mmm}$

$13 \mathrm{~K}$ : So I was like <I don't even wanna worry myself-- or make it seem like a concern means I don't want it done> Or like <why are you so concerned>

Despite their legitimate medical concerns, Keaton expresses their fear that their questions would undermine their thus far successful articulation of dysphoria in the constructed dialogue (Tannen 1986): in their view, posing questions risked communicating to the doctor that they do not meet the threshold for gender dysphoria, and that they are not sufficiently confident in their decision to pursue care. In electing not to take up their doctor's invitation to ask questions, Keaton appeals to the medical institution's connection between the need for care and an experience of dysphoria: "anyone with like enough dysphoria wouldn't care if their bladder prolapses" (line 11, emphasis added). Here, dysphoria itself is invoked as evidence that the procedure is wanted deeply enough regardless of outcomes or risks. Almost as a corollary to Jameson's apprehension of over-performing and displaying too much dysphoria, Keaton is mindful of meeting the bare minimum amount of sufficient dysphoria. Presence of dysphoria is itself inadequate; crucially, it must be the appropriate amount. In other words, not too big, not too small, but just right. As Borba observes, it is in these "textually constrained interactional performances which make the construction of a trusting healthcare relationship virtually impossible" (2017: 320) - one of many fundamental flaws in the transmedicalist practice of treating transgender people as patients simply by virtue of their being trans. Together, these narratives exemplify the utility in distinguishing dysphoria, as a very real experience for many trans people, from Dysphoria, an abstract institutional concept that must be deliberately constructed in a myriad of ways according to the confines of the transmedicalist care visit. This institutional rendering of Dysphoria, born in a setting of wariness or outright distrust between interactants, is fragile, a bubble that can be popped, and - as Keaton describes - the door that it opens slammed shut, its access-granting effects undone with a simple follow-up question.

Importantly, participant-collaborators' understanding of Dysphoria is informed by multiple domains. The 'authentic' trans patient is the model patient in this scenario, as established by not only the pressures of the medical institution but narratives circulating within trans communities that implicate non-Dysphoric trans people (and often non-binary people more generally) in a scarcity of access to medical technologies, holding them responsible for continued trans dehumanization. In light of both these institutional and intracommunity constraints, participant-collaborators endeavour to convey an approximate truth that includes sufficient information for the situation, providing nuance to previous analyses that characterize trans patients as duping their doctors (Speer 2010) or aligning with transnormative discourses in a way that forecloses their own agency (Borba 2017). Insofar as performances of Dysphoria are relevant to their doctor and required in order to access the desired care, they must be invoked. But by reworking Dysphoria as a means to their own ends, they deny doctors the semantic authority (McConnell-Ginet 2018) to define it; they make explicit the power asymmetry in their interactions and hold it up to critique.

With that said, in describing these practices as straightforward moments of resistance, we risk romanticizing or painting an idealized picture of what is ultimately a much more complicated situation. Critical race and Indigenous studies scholar Eve Tuck (2009: 419), in advocating for desire- rather than 
damage-based research, describes the notion of critical thirding", a thirdspace introducing a critical "other than" choice beyond the dichotomized categories of reproduction and resistance. In this case, practices of resistance simultaneously challenge doctor's semantic authority and, in a sense, rely on reproductions of linear, simplified, Dysphoric trans identities in a way that is deeply impactful for those seeking care. Participant-collaborators display a sharp awareness of this complexity in their critiques of transmedicalist assumptions, woven throughout their narratives of having indexed them in obtaining much-needed care.

As remarked by Wright (2016: 10), the very means of resistance may involve "speaking the language of power in order to make certain claims," though this can result in participants coming away from an interaction feeling "like they have not been understood or 'known' in some essential way" (Basso 2009: 136). For one, the expectation of normative performances that constrain trans people's expansive ways of being is a form of violence to trans people in itself. While for many the mantra that "existence is resistance" may ring powerfully true, the inability to exist without also having to resist can be exhausting. Yet as the excerpts above show, given the salience of transnormative, transmedicalist discourses for trans people's lives, they are often taken up and reworked as a resource for crucial access for those outside of their boundaries (Konnelly, 2021). As per Malatino (2020: 50), "we do what we need to do to keep going." Crucially, these strategic moves are a necessary response to the medicalization of transgender experience that constrains the possibilities for institutionally-approved ways of trans being. Thus, how doctors understand, evaluate, and interact with trans people is what must undergo a fundamental shift.

Acknowledgments. I would like to thank Archie Crowley and Atiqa Hachimi for reading and commenting on earlier drafts, and, along with Derek Denis, for discussions and co-thinking that have contributed greatly to the ideas presented here. I am also indebted to an anonymous reviewer for their incisive suggestions that have tightened my arguments. I also express my gratitude to the volume editors, Pocholo Umbal and Nadia Takhtaganova, as well as Naomi Nagy and Nathan Sanders. I especially thank Pocholo Umbal for the invitation to submit to this issue.

\section{References}

Abelson, Miriam J. 2019. Men in place: Trans masculinity, race, and sexuality in America. Minneapolis, MN: University of Minnesota Press.

Agha, Asif. 2007. Language and social relations. Cambridge: Cambridge University Press.

American Psychiatric Association (1980). Diagnostic and statistical manual of mental disorders: diagnostic and statistical manual of mental disorders, third edition. Arlington, VA: American Psychiatric Association.

American Psychiatric Association (2013). Diagnostic and statistical manual of mental disorders: diagnostic and statistical manual of mental disorders, fifth edition. Arlington, VA: American Psychiatric Association.

Bailey, Benjamin. 2000. Language and negotiation of ethnic/racial identity among Dominican Americans. Language in Society 29(4): 555-582.

Basso, Ellen. 2009. Ordeals of language. In Culture, rhetoric and the vicissitudes of life, ed. Michael Carrithers, 121-137. New York: Berghahn Books.

Bauer, Greta R. and Ayden I. Scheim. 2015. Transgender people in Ontario, Canada: Statistics from the Trans PULSE Project to inform human rights policy. London, ON: Trans PULSE.

\footnotetext{
5 As a white settler researcher, with my application of this concept comes the risk of 'white expert' (mis)appropriation and misinterpretation; this is especially important to acknowledge in linguistics, given the field's historically extractive relationship with Indigenous communities. My hope is that, in engaging with the intellectual contributions and critical insights of Indigenous scholarship, I offer not only greater theoretical understanding to the concerns discussed here but also a move towards greater interdisciplinary collaboration more generally.
} 
Bauer, Greta R., Jake Pyne, Matt Caron Francino, and Rebecca Hammond. 2013. Suicidality among trans people in Ontario: Implications for social work and social justice. Service Social 59(1): 35-62.

Benjamin, Harry. 1966. The transsexual phenomenon. Ann Arbor: Julian Press.

Borba, Rodrigo. 2017. Ex-centric textualities and rehearsed narratives at a gender identity clinic in Brazil: Challenging discursive colonization. Journal of Sociolinguistics 21(3): 320-347.

Borba, Rodrigo. 2019. The interactional making of a "true transsexual": Language and (dis)identification in trans-specific healthcare. International Journal of the Sociology of Language 256: 21-55.

Brown, Brian, Paul Crawford, and Ronald Carter. 2006. Evidence-based health communication. Maidenhead: Open University Press.

Bucholtz, Mary and Kira Hall. 2005. Identity and interaction: a sociocultural linguistic approach. Discourse Studies 7(4-5): 585-614.

Burke, Mary C. 2011. Resisting Pathology: GID and the contested terrain of diagnosis in the Transgender Rights Movement. In Sociology of diagnosis: Advances in medical sociology, ed. P.J. McGann and David Hutson, 183-210. Bingley: Emerald Group Publishing Limited.

Candlin, Christopher N. and Sally Candlin. 2003. Health care communication: A problematic site for applied linguistic research. Annual Review of Applied Linguistics 23: 134-54.

Cromwell, Jason. 1999. Transmen \& FTMs: Identities, bodies, genders, and sexuality. Urbana, IL: University of Illinois Press.

Dame, Avery P. 2013. "I'm your hero? Like me?" The role of 'expert' in the trans male vlog. Journal of Language and Sexuality 2(1): 40-69.

Devor, Aaron. 1996. Female gender dysphoria in context: Social problem or personal problem. Annual Review of Sex Research 7(1): 44-89.

Fairclough, Norman. 1989. Language and power. London and New York: Longman.

Fairclough, Norman. 1995. Critical discourse analysis: The critical study of language. London and New York, NY: Longman.

Fairclough, Norman. 2013. Critical discourse analysis: The critical study of language. New York, NY: Routledge.

Garrison, Spencer. 2018. On the limits of "trans enough": Authenticating trans identity narratives. Gender \& Society 32(5): 613-637.

Johnson, Austin H. 2015. Normative accountability: How the medical model influences transgender identities and experiences. Sociology Compass 9(9): 803-813.

Johnson, Austin H. 2016. Transnormativity: a new concept and its validation through documentary film about transgender men. Sociological Inquiry 86(4): 465-491.

Jones, Rodney H. 2013. Health and risk communication: An applied linguistic perspective. London: Routledge.

Jones, Rodney H. 2015. Discourse and health communication. In The handbook of discourse analysis, ed. Deborah Tannen, Heidi E. Hamilton, and Deborah Schiffrin, 841-857. Hoboken, NJ: John Wiley \& Sons.

Jones, Lucy. 2019. Discourses of transnormativity in vloggers' identity construction. International Journal of the Sociology of Language 256: 85-101.

Kiesling, Scott F. 2007. Men, masculinities, and language. Language and Linguistics Compass. 1(6): 653673.

Konnelly, Lex. 2021. Nuance and normativity in trans linguistic research. Journal of Language and Sexuality 10(1): 71-82.

McConnell-Ginet, Sally. 2018. Semantics and pragmatics: Blurring boundaries and constructing contexts. In The Oxford handbook of language and sexuality, ed. Kira Hall and Rusty Barrett. Oxford: Oxford University Press.

Malatino, Hil. 2020. Trans care. Minneapolis: University of Minnesota Press.

Milroy, Leslie. 1987. Language and social networks. New York: Blackwell.

Obedin-Maliver, Juno, Elizabeth S. Goldsmith, Leslie Stewart, William White, Eric Tran, Stephanie Brenman, Maggie Wells, David M. Fetterman, Gabriel Garcia, and Mitchell R. Lunn. 2011. Lesbian, 
gay, bisexual, and transgender-related content in undergraduate medical education. Journal of the American Medical Association 306(9): 971-977.

Parsons, Talcott. 1951. The social system. New York: Free Press.

QSR International Software 2018. NVivo 12 for Mac. Burlington, MA: QSR International.

Sharman, Zena. 2016. The remedy: Queer and trans voices on healthcare. Vancouver: Arsenal Pulp Press.

Speer, Susan and Rebecca McPhillips. 2013. Patients' perspectives on psychiatric consultations in the Gender Identity Clinic: Implications for patient-centered communication. Patient Education and Counseling 91(3): 385-391.

Speer, Susan. 2010. Pursuing views and testing commitments: Hypothetical questions in the psychiatric assessment of transsexual patients. In Why do you ask? The function of questions in institutional discourse, ed. Alice Freed and Susan Ehrlich, 133-158. London: Oxford University Press.

Speer, Susan. 2011. On the role of reported, third party compliments in passing as a 'real' woman. In Conversation and gender, ed. Susan Speer and Elizabeth Stokoe, 155-182. Cambridge, U.K.: Cambridge University Press.

Spivak, Gayatri Chakravorty. 1988. Can the subaltern speak? Basingstoke, UK: Macmillan.

Tannen, Deborah. 1986. Introducing constructed dialogue in Greek and American conversational literary narrative. In Direct and indirect speech, ed. Florian Coulmas, 311-332. Berlin: Walter de Gruyter.

Tuck, Eve. 2009. Suspending damage: a letter to communities. Harvard Educational Review 79(3): 409428.

van Dijk, Teun. 2015. Critical discourse analysis. In The handbook of discourse analysis, ed. Deborah Tannen, Heidi E. Hamilton, and Deborah Schiffrin, 466-485. Hoboken, NJ: John Wiley \& Sons.

Vipond, Evan. 2015. Trans rights will not protect us: the limits of equal rights discourse, antidiscrimination laws, and hate crime legislation. Western Journal of Legal Studies 6(1): 1-20.

West, Candace and Don H. Zimmerman. 1987. Doing gender. Gender \& Society 1(2), 125-51.

Wodak, Ruth. 1996. Disorders of discourse. London and New York, NY: Longman.

Wright, Fiona. 2016. Resistance. In The Cambridge encyclopedia of anthropology, ed. Felix Stein, Sian Lazar, Matei Candea, Hildegard Diemberger, Joel Robbins, Andrew Sanchez, and Rupert Stasch, 113. Cambridge: Cambridge University Press.

Zieger, Avery E. F. 2016. Transgender identity and ethics of care: Narrative analysis of transgender identities and experiences of care in Saskatchewan. MA thesis, University of Saskatchewan.

Zimman, Lal. 2020. Transgender language, transgender moment: Toward a trans linguistics. In The Oxford handbook of language and sexuality, ed. Kira Hall and Rusty Barrett. Oxford: Oxford University Press. 